\title{
Control by quality: proposition of a typology
}

\author{
Patrick PUJO $^{(1)}$, Maurice PILLET ${ }^{(2)}$ \\ (1) LSIS : Laboratoire des Sciences de 1'Information et des Systèmes, Av. Esc. Normandie Niemen, 13397 Marseille cedex 20 FRANCE \\ Tel. +330491056055Ｆax. +330491056033Ｅ-mail. Patrick.pujo@univ.u-3mrs.fr \\ ${ }^{(2)}$ LLP : Laboratoire de Logiciels pour la Productique, Domaine Universitaire, F74016 Annecy cedex FRANCE
}

\begin{abstract}
.
The application of Quality tools and methods in the industrial management had always a fundamental impact on the control of production facilities. It influences on the behavior of concerned actors, while introducing the required notions and formalisations, in particular in production systems little automated or not, that constitute a large industrial activity part.

Several Quality approaches followed each other in workshops, and thus find again in their control. In this paper, the authors present a typology of different approaches having had some successive and notorious influences on workshop's control, as the statistical process control, the quality assurance and the continuous improvement.
\end{abstract}

At first, the authors propose a parallel between production control and quality organization. They note a hierarchical organization of these two systems of management, with, to each level, the notion of feedback loop. This notion is fundamental in all decision making. They also organize their subject around the operational, tactical and strategic levels, by describing for each level the main methods and tools for control by quality.

This panorama of tools and usable methods for the control starts by the operational level, with the SPC, Taguchi techniques or the ' six sigma' approach. At the tactical level, we recover a quality system approach, with a documented description of introduced procedures in the enterprise. The management system can refer here to the assurance quality, to the TPM or to a management by the total quality. The formalization using procedures of decision rules governing the control of processes brings a better validity of these rules. It allows to improve the reliability of these rules and to consolidate them. Thus it opposes the human behavior intrinsically fluctuating of operators' control. Finally, the strategic control by quality is detailed, and then the two main approaches, by continuous improvement and by proactive improvement, are exposed.

To finish, the authors observe that to each of these three levels, the continuous improvement of processes which is a component of the Total Quality, becomes an essential preoccupation for the control. So, the idea which was coming out is the recursive utilization of the Deming cycle for control by quality. 


\section{Introduction}

The fact to bring in quality tools and methods in the industrial management had a fundamental impact on the production equipment and particularly on the concerned people's behaviour, bringing in notions of strictness and formalism in the decision making. This impact will soon concern small or medium-sized ind ustrial companies, particularly when their production system isn't much automated or not at all.

Among all the company functions, the quality is doubtless the one, which has the most, evolved in the course of the two last decades. This evolution has definitely shown the inadequacies of a mere quality control, and today the outcome is a real control by quality.

The first evolution concerned the manufacturing control: one of the first ideas was that quality could be reached applying the strict rules of production inspection achieved. But the limits of this notion appeared: the quality doesn't only regard the product but overall the way the work is organised and managed. Then, that's the moment when the control by quality began to have a major impact on the company's management. The formalisation in procedure form of decision rules governing process control led to a larger thought about these rules validity, hence an improvement of their reliability and their stabilisation, thwarting thus the human behaviour, fluctuating, of command operators. The visible outcome of this new approach is the implementation of quality assurance system.

However, a simple rules formalisation isn't enough to ensure control by quality: the quality is also progressing and progress must be managed (Stashevsky et al. 2000). Then, control by quality must consider two complementary approaches: formalisation of decision rules must be completed by the implementation of a continuous improvement system of these rules.

At first, a description of the various approaches of control by quality, as well on a conceptual point of view than on the systemic point of view. Then, we'll talk about how all this is taken into account at the different decision levels of companies, and besides implemented in a "ad-hoc" way in workshops thanks to methods and tools associated with these concepts.

\section{Duality between control and quality}

Very often, control and quality have been opposed whereas, on the contrary, these two approaches are perfectly complemented, if not similar. In firm, the visible outcome of this opposition is that the person in charge of manufacturing only worries about his short-term production whereas the quality manager tries to formalise the know-how and methods of the firm.

\subsection{Definitions}

In order to define well the duality between control and quality; let's first go back to definitions:

- quality: "the totality of features and characteristics of a product or service that bear on its ability to satisfy stated or implied needs",

- control: "function aiming at optimising the efficiency of the use of a production entity".

On the one hand, the control's goal is to increase productivity, and so to have a greater ability to product and to be able to increase one's market part; on the other hand, the qua lity's goal is to satisfy customer's needs and so to increase their number. The global and common aim is the firm efficiency improvement. Besides, the analysis of the various elements of the SPR (Synthetic Performance Rate, expressing the ratio between the production system potential and what it really does) shows that the SPR improvement necessary requires an improvement of control by quality. 


\begin{tabular}{|c|c|}
\hline SPR Elements & Examples of improvement actions \\
\hline Stop for breakdown & $\begin{array}{c}\text { Preventive maintenance, improvement of process } \\
\text { parameters supervision }\end{array}$ \\
\hline Absenteeism & $\begin{array}{c}\text { Improvement of working conditions, worker's } \\
\text { sharing of the profits }\end{array}$ \\
\hline Scraps, alteration & Product quality improvement, process reliability \\
\hline Control & $\begin{array}{c}\text { Control frequency reduction thanks to a better } \\
\text { process control or setting up of preventive system }\end{array}$ \\
\hline Supplying & $\begin{array}{c}\text { Quality improvement on upstream machines, } \\
\text { quality assurance suppliers }\end{array}$ \\
\hline
\end{tabular}

Table 1. SPR's improvement

So, the two approaches have strictly the same goal, it's useless to oppose them. On the contrary, we'll try to show how to make these two approaches converge and thus become complementary.

\subsection{Relations and comparisons between control and quality}

Before tackling this demonstration in detail, we already notice that we can see a parallelism between the hierarchical levels of control and the quality approaches hierarchy.

Indeed, the complexity of the production system management brings about in both case a decomposition of the problematic and their aggregation in strata where can be expressed in a coherent way a point of view of process observation, a behaviour model and decision rules. This decomposition can be based on the classic one of the production system (factory, workshop, cell, and machine) or on the associated production tasks one (Daihani et al. 1993). This can be represented in a pyramidal form of stacking of these strata, with on the one hand aggregation levels, going from a global point of view to a details taking into account, and on the other hand, temporal horizons.

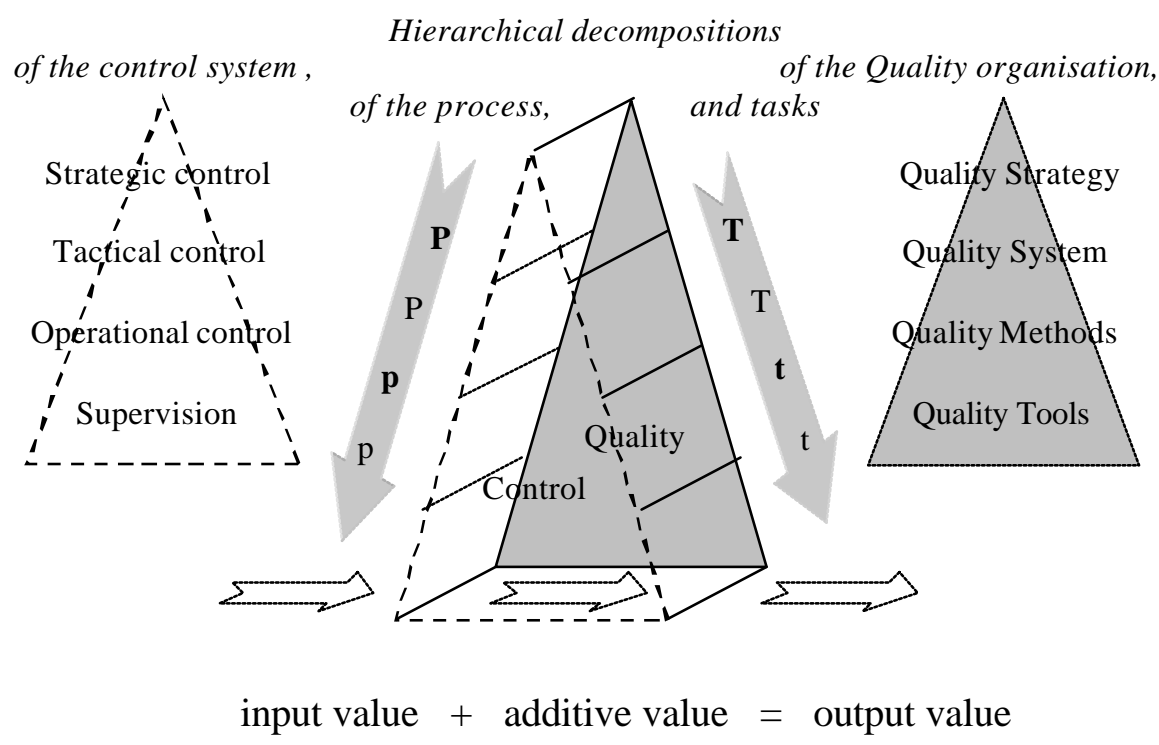

Figure 1. Parallelism between the hierarchical organisations of the control and the quality 
In a company, it's quite common to find two hierarchical management systems, quasi independent, are in charge of control with a point of view resolutely directed to the allocations of tasks or resources' optimisation, and the other one directed towards the quality research.

Notions of strategic, tactical and operational control are well known. As is the case with control, management by quality is a "Top/Down" process, which must be applied by the management team, clearly defining a quality strategy.

Then, the visible outcome of this strategy must be the choice of a quality system, which will represent the formalisation of actions leading to the quality achievement. The "quality methods" linked with "quality tools" will finally represent the quality system realisation in the field.

In both cases and at every aggregation level, we find the notion of feedback loop associated to the decision making, describ ed in figure 2. A decision situated at an aggregation level $\mathrm{n}$ is translated into an action for the lower level. Then, this decision depends on orders coming from the upper level and information coming from the lower level. At every level, the information s filtered and summarised in order to be transmitted to the upper level.

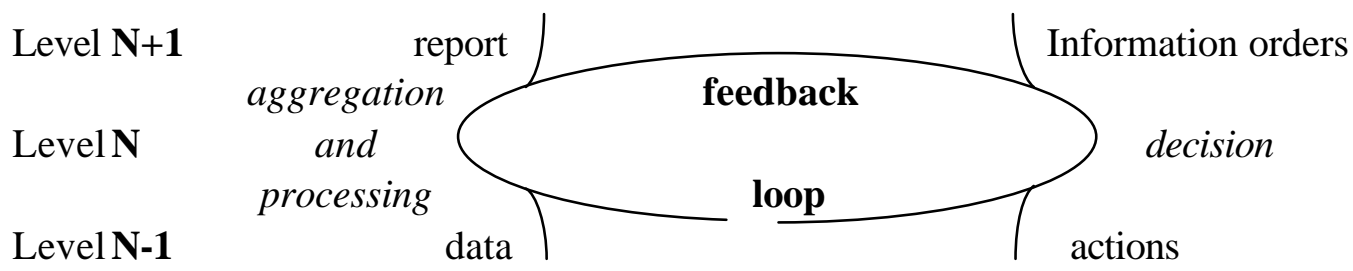

Figure 2. Feedback loop at an aggregation level

We talk about control by quality when respective requirements of the control and quality functions are taken into account simultaneously in a same feedback loop. Particularly, we'll find the use of quality tools or methodologies to facilitate control and introduction of PDCA cycle from Deming for the continuous research of its improvement (Juran 1990).

A complementary order for the control is given by product quality that the customer's hope. Then, the control by quality is found at every level strategic, tactical and operational and its fit is realised from two supplementary feedback loop:

- One, internal, enables to assess the quality system relevance thanks to intern audits,

- The other one, external, gives the assessment of quality releva nce from surveys carried out with customers.

We've established that the control by quality results from the declension and merging of two complementary visions of production management. The global aim is to improve the company efficiency and this is found at the strategic level where the management must apply good directing and judicious political choices. Then, this directing has to be formalised at the tactical level, in a management system form. The development at the operational level of this system is made through quality methods and tools they use and which are well controlled by companies. Thus, in the next part, we'll follow this logical sequence of concepts. Every paragraph will correspond to an aggregation and decision making level. Everyone will contain a description of a quality contribution in the decision loop of the control and a panorama of quality plans of action usable at this decision level. 


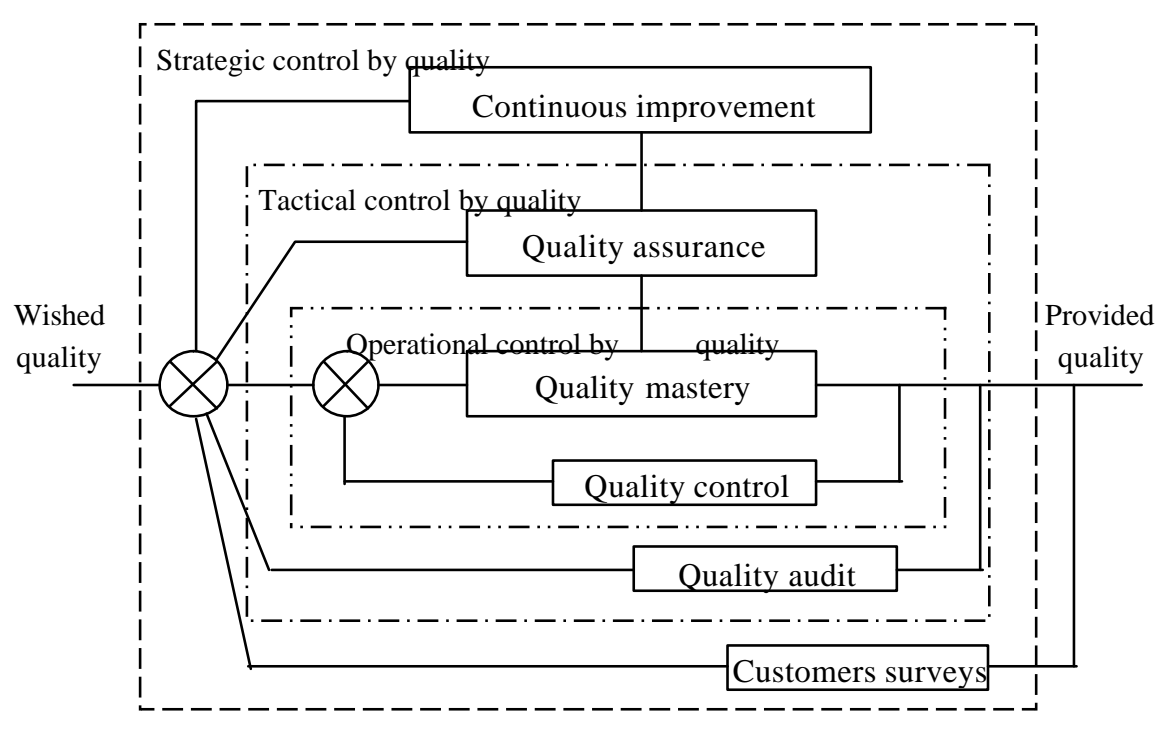

Figure 3. Multiple feedback loop in a context of control by quality

\section{Operational contro 1 by quality}

That's thanks to specific quality methods and tools that a quality approach can have a real impact on the production operational development (Mizuno 1988, Matsuda 1993). These methods and tools are various, so we'll introduce characteristic elements of these methodological approaches, as well as examples commonly used in companies.

\subsection{Characterisation of a quality approach for the operational control}

Many criteria enable to class quality approaches used in the operational control. First of all, it agrees to distinguish methods of tools. A quality method is composed of a logical and organised succession of principles in order to evaluate, control or improve the quality of the performance of process aspect. On the other hand, since a tool is only the technical mean of an operation, it's generally easier to establish it in production and to use it, but it is less efficient. Then, the quality approach of the operational control can be considered according to several temporal horizons. Short-term, the methods and tools of the operational control by quality are aiming to anticipate the appearing of non-faithfulness on the workstation and to treat them when defects occur. As it is the case for workstations under autonomous control by self-inspection or statistical approach. Long-term, the goal of these operational control approaches is the process performance improvement and its variability reduction, thanks to a modification of the control or process parameters. Several approaches exist to control this improvement and must offer the best balance of accuracy and utility (Knowles et al. 2000). We'll detail the two approaches, which seem to be the most significant among all these methods: the Taguchi technique approach and the method of problems resolution used by quality system "six sigma". Finally, it's advisable to know if the approach in question is specially directed towards the launch of production actions or their parameters adjustment, or then if it is intended for following the production through, that's to say for the information aggregation in order to help decision. 


\subsection{Panorama of methods for the operational control by quality}

\subsubsection{Operational control by Autonomous Process Control}

Autonomous process control is certainly the most effective method of operational control, in a quality point of view. Contrary to what it is a generally acknowledged fact; autonomous process control doesn't only consist in measuring or visual inspecting production by operators (selfinspection). Autonomous process control is defined like a local loop of quality control and we'll detail its running mechanisms.

Placing a work station in autonomous control consists in giving at this station all the necessary means to master its production quality, respect delays and provide the minimum production cost of the product. It begins with a fine analysis of all the variability causes, which can act on the three aspects delay, quality and cost. On the two essential processes to master, the production process and the measure process, the fundamental causes can be grouped thanks to the Ishikawa diagram or CEDAC tool (Fukuda 1990).

After having made the most exhaustive as possible analysis of variability causes, thanks to a Pareto's diagram for example, we must check that every cause can't have an influence on mastery of the process quality. In case of potential leeway, an action must stop in a satisfactory way, either the cause appearance, or its consequence. One of the most used tools to realise study of such a workstation is the FMEA Analysis. It consists in giving the failure mode according to its three aspects: the frequency of the cause appearance, the seriousness of its effect and the efficiency of the detection of the cause consequences.

Within a quality system, autonomous process control is linked with an important documentary management for the mastery of the quality of the workstation. We can quote, for example, the work card, which formalises the retained procedure, the first level maintenance plan, which formalises maintenance of the workstation and the equipment and the monitoring plan (KoetlukFlorescu 1995), which formalises these decided checking. In the workshop, we'll also find some generic rules in a procedure participating to the quality achievement by operational control: treatment of non-accordance, information return on sticking up form of obtained results, ranging of work stations (Osada 1991)...

\subsubsection{Operational control by SPC ( Statistical Process Control)}

To control correctly a production process, it's necessary to know some statistical rules and to implement tools making explicit easily their application in the control: it is called Statistical Process Control (SPC). Its origin is dated of 1931 with the first Stewhart's publications (Shewhart 1931, Pillet 2000), and shows the start of the quality concept in industrial activities. Its effective broadcast in companies comes later and is due to Deming's work after the Second World War.

Today, the SPC's concept implementation is generalised at every industry's areas under the impetus of the car industry and the electronics area. In order to explain easily these running rules on workstation, we have a graphic tool: the control chart, which is a tool, showing the chronological evolution of a production characteristic. A control chart enables to realise several kinds of causes, such as the decentring or the evolution of process spread. So, the control chart is a really tool of control and process analysis. But, besides this help to control, the SPC is also a powerful tool of process analysis and improvement. By crossing between common causes detected by the control chart and occurred events on the work station, it's possible to establish a 
corresponding matrix between causes and effects, favouring thus a better process knowledge and so leading to its improvement.

Like every system of control, the SPC has a system of performance measurement enable to follow the initial state and carried out progress: the capability indicators $\mathrm{Cp}$ and $\mathrm{Cpk}$, which permit to position the process beside the required tolerance for the product achievement. At the close of a product design, every characteristic is the subject of a tolerance, which conveys on the one hand the product ability to operate, and on the other hand, its ability to be manufactured. Yet, because of their intrinsic and unavoidable scattering, production processes don't enable to target and get strictly a nominal value for a given characteristic. So, it's compulsory to accept variations around this target, settling tolerance limits.

\subsubsection{Operational control by Taguchi technique}

According to Taguchi (Taguchi 1987), the reduction of the process variability (figure 5) is considered dissociating three kinds of variables:

- The signal variable, which represents the process order; the process goal is, according to Taguchi, to obtain a characteristic $\mathrm{Y}$ of the process output which would be a linear function of the order variable.

- The noises parameters, which represents the set of uncontrollable parameters and which will vary independently of the operator's will.

- The controllable parameters, which can be fixed by the operator.

The optimisation goal consists in finding the optimal configuration of controllable parameters in order to limit noises factors' influence and to get the greatest linearity of the result $\mathrm{Y}$ according to the signal factor $\mathrm{X}$.

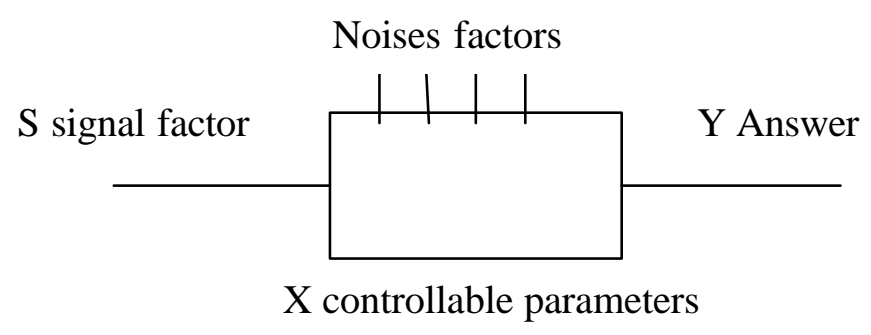

Figure 5. Model of a process to control, according to Taguchi

The optimisation is realised using limited experiences plans based on acquired knowledge thanks to the study of the controllable parameter influence for different configurations of the signal factor $\mathrm{S}$ and for different configurations of the noise factors. The optimisation consists in finding the controllable factors' configuration in order to decrease the scattering around the optimal linear function. The result of a dynamic optimisation according to the Taguchi's approach leads to a greatest process ability to be controlled, to greatest process robustness in relation to the noise factor and to a better process capability.

\subsubsection{Operational control with the "six sigma" approach}

The method for solving problems used in the quality system "six sigma" is another example aiming at the process improvement. The proposed method is divided into six stages, which remind the Deming's cycle (Forrest 1999, Harry 2000). 
This kind of processes has several advantages:

- It compels the user to respect a sequential processes in his approach of variability reduction,

- It clearly brings to the fore the measure importance, being a precondition to the continuous improvement,

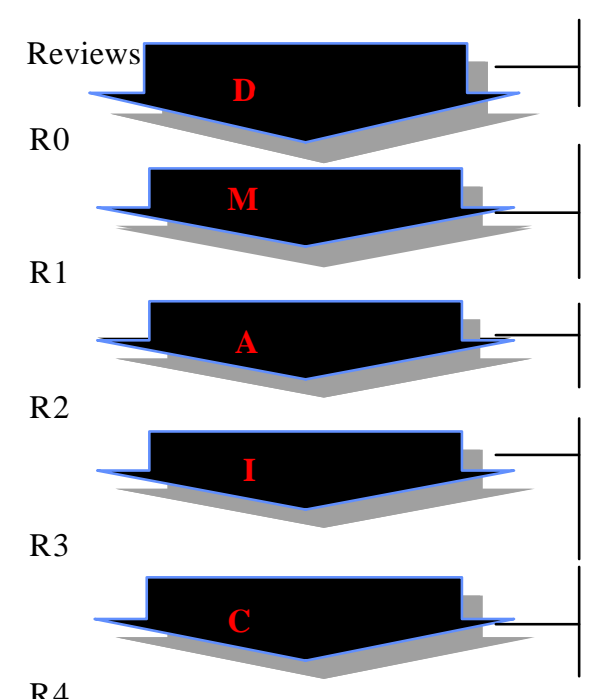

Defining the problem correctly, the limits of calling into question, the working group

Finding a way of quality measure and checking the way of capability measure. Collect facts.

Examining, analysing data, proving statistically speaking the influent factors

Testing out, modifying, improving, optimising and proving statistically speaking that improvements are efficient

Applying the solution,

Putting it under supervision

Figure 6. Method for solving problems "six sigma"

- It implies all the partners through a working group, but also the management by means of review which must be realised to authenticate each stage,

- It forbids modifications on the process before the stage "improving", avoiding in this way, obvious solutions a priori, but which only move the process away from a sturdy running point,

- It imposes to put under checking the obtained solution,

- It imposes to set up the whole necessary actions to make the solution long lasting in the time.

\section{Tactical control by quality}

Tactical control consists in translating strategic decisions level with operational departments. Several families of methodological approaches directed towards quality enable to obtain more robustness and efficiency levels with the control:

- formalising decisions making and checking their suitability by comparison with a referential,

- improving decisions making and practices, thanks to staff involvement together in progress group and relying on a formal processes of continuous improvement,

- having a prevention methodology aiming at eliminating at the source every cause of nonquality.

In reality, these approaches complement harmoniously one another and the true control by quality consists in setting up simultaneously several of these strategies. The processes which are today the more often practiced are the use of norms ISO 9000 like referential, the use of a 
processes six sigma to progress and/or the setting of the Total Productive Maintenance.

\subsection{Formalisation of a quality system for the tactical control}

The common point between these various processes is the need of clearly making explicit the decision rules, which organise the company's control, and particularly the one of its production system. It's question of making these rules intelligib le for everyone, and so applicable. Nothing other than the fact to write the company's practices, and then to conform to what it is written, enables to increase the reliability of the control system. In order to confirm this idea, we can list some examples of failures, which could lead to a non-similarity, and this can occur in all the company's departments:

- a company has accepted an order without having truly evaluated if the control system could provide enough resources to realise the work, and the company is unable to deliver the customer,

- a plan has been modified, but the control system has not taken into account this change and the new technical documents, and the manufacturing workshop goes on working with old plans,

- an equipment goes on extremely often, this generates non-similar products and the linked waste, and this disturbs the course of the control, which must implement additional tasks of alteration or new launching in production, in order to compensate for loss in semi-finished products.

Moreover, we can found some criteria allowing the definition of the quality assurance system in (Adams 1999). The whole of these decision rules are so described in a documentary system which is useful before all for the intern company use. We find the organisation set up at the tactical level and detailing the entire arrangements, which enable the company to run with quality requirements. We'll talk so about quality documentary system (QDS) of the company's quality system. A QDS is composed of various technical documents of the company's management; we can schematise it on a hierarchical pyramid form (figure 7), on which top we find the quality manual. This quality manual describes the general structure of the quality system and refers to the entire used procedures. Each procedure enables to formally specify and relatively abstract the way to perform an operation or to manage a process, describing what must be done and who must do it, where, when, how and with which resources. These procedures are translated into operating methods and other technical instructions, so as to be directly exploitable on workstations and to precisely formalise the company's know-how. We also find the type sheets to note results, which enable to give information to the system about the quality really obtained. The documents of this last decomposition level make up the pyramid's root of the QDS.

This way of formalising the quality system is found whatever the method of tactical control chosen or laid down by choices of many kinds of management by quality made at the strategic level.

\subsection{Overview of the tactical quality control styles}

Three systems are going to be examined.

\subsubsection{Tactical Control by Quality Assurance}

This system aims, on one hand, to improve the customer service provided and on the other hand, to decrease the number of internal malfunctions. Assuming the firm's quality control 
system is efficient, it could be used to show to the customers the company's efficiency to accomplish its tasks (Curkovic 1999).

Seeing how difficult it was to estimate a supplier's quality through his deliveries, important decision-makers established the quality assurance and this for several reasons:

- impossibility of detecting some bad products out of millions evens by complete testing of deliveries,

- increasing rate of product flow makes it impossible to control some components before placing them on the production line,

- to eliminate wasting, operations giving no added value like tests tend to be suppressed.

To ensure deliveries quality without undergoing tests, the firm suppliers have to undergo audits. This led to the normalisation of the insurance quality system through norms such as ISO 9000, revised in 1994 and in 2000. This normalisation is the description of the major dispositions a firm needs to take in order to as sure product and service quality. In such a context, the certification by a third uninterested party, i. e. by a certification organism, independent and legally empowered was implemented.

The succeeding firm receives a certificate which has to be renewed after a specific period of time and which can be presented to customers to prove the good level of its control system by quality. The answers to the recommendations are found in the quality manual.

\subsubsection{Tactical control by Total Productive Maintenance}

Usually, a maintenance service stands by during production ready to intervene whenever a fault appears. In their permanent quest for excellency and their refusal of wasting, Japanese firms developed, in order to reach the paradigms of the zero defect and the zero breakdown, a technique for preventing and anticipating systematically any malfunctions named Total Productive Maintenance (TPM) (Shirose 1994, Wang et al. 2001).

Its basic principle is simply that the product will be good if the production process is good.

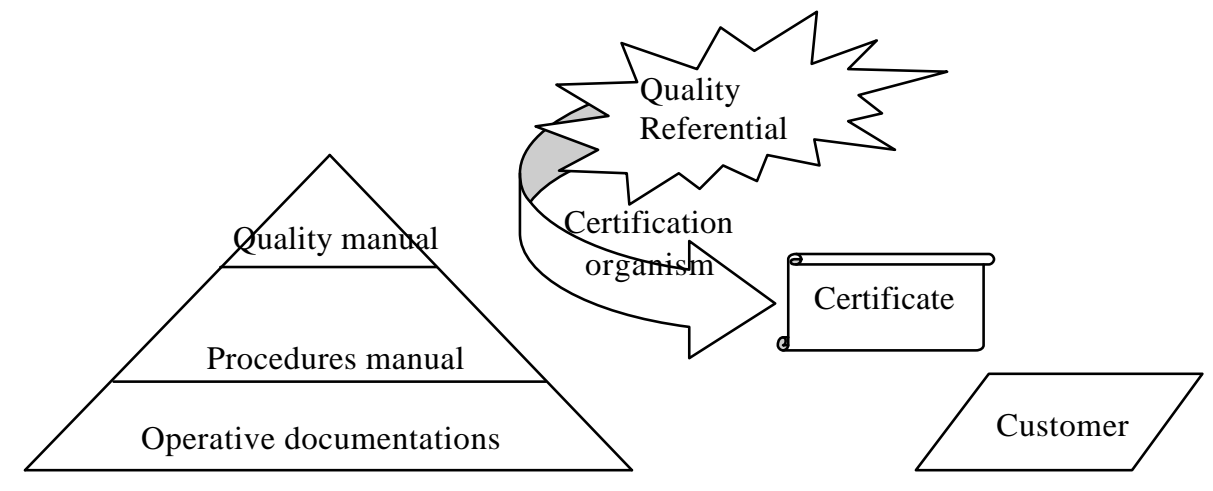

Figure 7. Quality certification by a third party

Therefore, an in-depth control of the production system should bring about good products. This means re-organising the maintenance system completely and reducing the amount of work done by technicians. Part of the maintenance, simple and recurrent maintenance tasks, will thus be imparted to machine operators.

The role of the maintenance department will only consists of three major functions: making complex, exceptional and/or delicate interventions and maintenance on machines whose 
operators have not completed their training, managing and coordinating the maintenance done by operators, training and afterwards following the work of each operators and at the same time editing operating methods for each operator's tasks.

The operator can schedule freely the supplementary maintenance tasks and his usual production control tasks. However, some constraints have to be respected and some preestablished results produced. TPM tasks can have different forms:

- periodic preventive maintenance tasks requiring small interventions that are plan and renewable,

- contingent tasks of small and average curative maintenance, that implies an event-triggered control.

This means that the quality system is perfectly mastered. The TPM documentary system includes the TPM manual, which describes the overall architecture of the system, the specific procedures and goes as far as the different operating methods applied on the workstations. However, an operator can only intervene for maintenance tasks he was trained for therefore an operating procedure is applicable only when the operator is trained for it.

\subsubsection{Tactical Control by Total Quality Management}

This type of quality control is more dynamic and is now integrated in the ISO-9000 standards (2000 version). Many studies showed this evolution (Auer et al. 1996, Mahoney et al. 1994). This new version considers that the overall quality of a firm is the result of the quality of its key procedures, which produce the added value of the product. Therefore, the firm must identify its key procedures and prove that everything is done to ensure the quality of these procedures and their continuous improvement. This will allow small and average size firms to organise their decision making systems more simply and thus more easily. It is thus a further step for Total Quality Control systems. The performance is obtained through best practices (Ismail et al. 1998).

To preoccupations linked to control of the production procedure, it adds wider considerations linked to management of human resources, to the position of the firm in the industrial environment and to interest of the various parties forming the environment of the firm (employees, customers, sharers and society in general).

This quality assurance approach has the objective of integrating differents sub-standards existing in a unifing manage ment system (Wilkinson et al. 2002). In this context, the TQM manual describes all the TQM standard practices of the firms. Edited by the managing team, this manual is a virtual toolkit for all the operating actors of the firm. The latter can then edit the applications manual that describes factually and synthetically the real situation of the practices established by the managing team. These are the same as the procedures applied in the workshops. The ISO 9000-2000 standard remains oriented towards the management of the processes. However, it shows the advantage of an organisational structure going from strategic level of decision to an operating level. A diagram presenting this structure is shown in figure 8 .

\section{Strategic Quality Control}

A strategic view of the management of the production system becomes essential for the long life of a firm. Several points of views- economical, technical... - must be examined and it gives birth to strategic decisions. When the organisation of this control level allows obtain a synthesis of these different points of views, being coherent with the aim of improving the firm, we say it is a Strategic Quality Control system. 


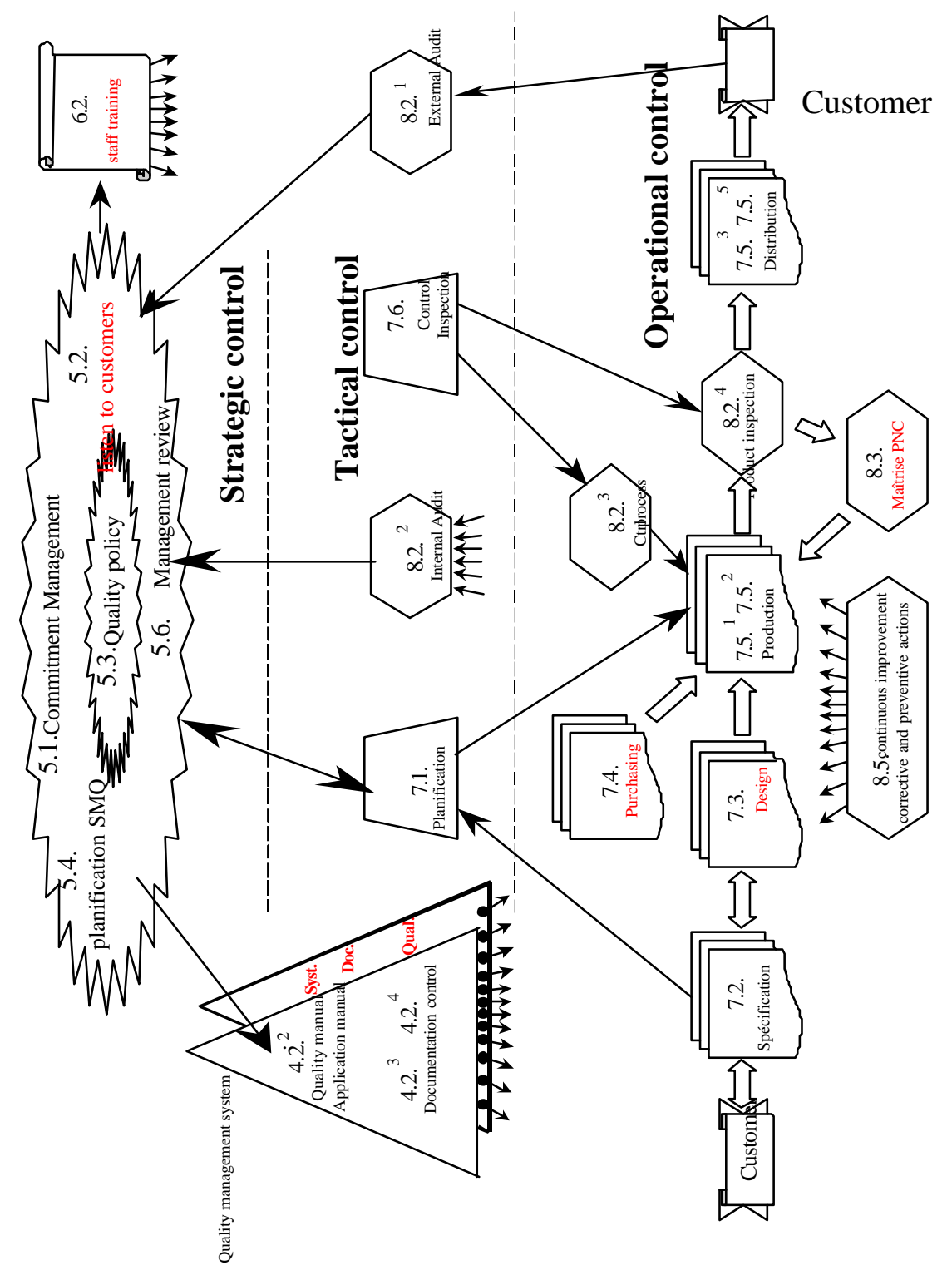

Figure 8. Total quality control architecture in ISO 9000-2000

This permanent mechanism for strategic decision making allows the management of the evolution of the production system. It can take two forms. The continuous improvement of the production processes, that is establishing a collective method to make progresses in various fields. The proactive improvement that is making continuous progress by focussing on different directions depending on the evolution of the firm, which faces the new, market needs.

This mechanism must be completed by the ability of this decision making level to bring to light the important factors bringing about this need for evolution. This is firstly possible through 
the observation of concurrent in the same industrial environment and secondly by using a recurrent methodology such as the Deming cycle. However, some first axioms of Deming's theory correspond to this level of control (Hilmer et al. 2001): organization viewed as a system, long-term view, need for co-operation...

\subsection{Organising a quality approach to strategic control}

Strategic control by quality implies research of efficiency by the managing team. They must not confuse the control's quality, which deals with how well the system of production is managed, quality control, which manage actions and/or plans under projects management form, and control by quality, which consists of implementing quality tools in the processes of decision making. This operation should be triggered by the management team and applies in each department of the firm. For that, the control by quality will take the form of a feed back structure whose centre will be the firm itself. Figure 9 describes the strategic control structure.

Concepts used in automatic control will have to be used: the necessity to define the signal of the control loop in order to elaborate the control actions taking into account the obtained results.

\subsubsection{Preliminary definition of the strategic aims}

The input of the control system is clearly defined as the engagement of the management to attain the predefined strategic aims. A part of the firm's costs and internal operations should be oriented towards those aims and then it should have an effect on customers' satisfaction, the firm's external image and positioning on the market against concurrency. Customer and the market needs impose the level of quality required.

\subsubsection{Context of strategic control}

Some values must be shared by each part of the firm so that desired quality of products can be obtained. Thus, the firm's strategy should be to search the strong values that will determine the base of their quest for quality and on, which is built the firm's culture, and the way it operates. The corresponding control actions can be, for example, linked to the firm's internal communication through which the firm expresses its strategic choices.

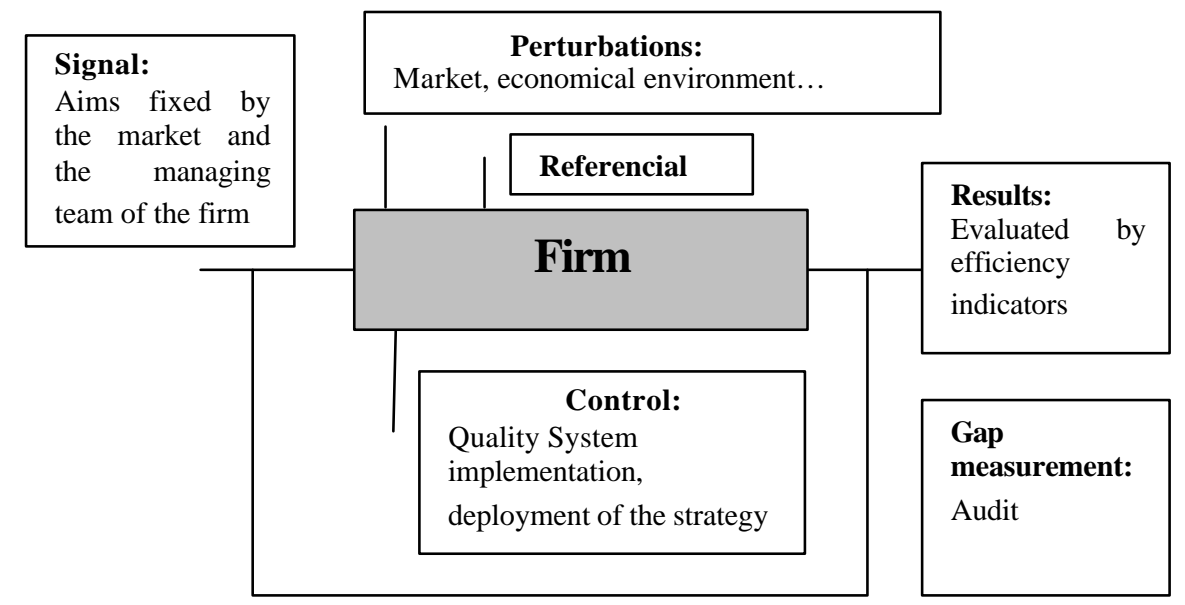

Figure 9. Strategic control by quality 
Secondly, management by quality cannot be implemented immediately; it has to be developed with time, and needs specific means and aim to reach predefined objectives. The strategic role of the management team is, after defining the aims, to make the right choices of the operating methods, of tools, of referential, of the quality systems... and to follow their spreading over the firm at a tactical and operational level. This includes several phases: start, construction, application and maintenance for each of the choices. Furthermore, supporting actions should be scheduled such as planning the training of the staff. The tools and methods used by every actor should be appropriated by the firm for trigger the cultural integration of the strategic orientations. That requires a high investment in training.

\subsubsection{Organising strategic control by quality}

As we have seen, the actors of the system must do it thus it is essential to define each one's role and responsibilities. Several organisation structures can be used.

If the aims are not concrete, the actors will not be able to grasp them, to motivate themselves and finally to measure how much progress they have achieved. To be efficient, the strategy should be to manage the control with a precise scheduling, which implies defining intermediate objectives.

\subsubsection{Choosing a quality standard reference}

As said before so as to avoid several methods of quality control, a referential should be followed by all firms; the most famous of them is ISO 9000 but there exists other more general referentials such as the EAQM and specific ones like the ISO TS 16949 norm which deals only with vehicles suppliers. This referentials simplifies greatly the customer-supplier relations because a unique certification is a proof of quality for all customers and all suppliers can use a unique reference system. However, some firms can choose to design their own reference system according to the quality constraints imposed by the managing team.

The adopted quality strategy when projected on the production system will be forced to use the tools and methods, which respect the constraints imposed by the quality referential adopted. The managing team should therefore do choosing these methods and tools itself.

\subsubsection{Evaluations and use of these evaluations}

Results obtained by the firm can only be evaluated by using performance indicators able of evaluating the progress made. It's a basic principle: no progress without measures. We can thus know if the quality strategy is efficient and well implemented. These indicators will have to measure not only the customer level of satisfaction but also the progress made in term of rejected products cost, environmental effects, integration of the firm in society, internal human relations... The aim of quality is not only the product's quality but also the good and continuous development of the firm.

The indicators measures should be significant so those pertinent conclusions on the firm's evolution can be made from them.

Using the measures made to verify the quality strategy would bring about the realisation of audits to compare reality to referential system chosen. First, these audits must be performed internally then completed by external audit done by customers or specialised organisms. 


\subsection{Survey of strategic control by quality styles}

Strategic control by quality aims to the recognition of the excellent image of the firm and this means improving the working system of the firm and thus its results. This level of decision making involves the Total Quality Management. We have met this style in the tactical and operational levels. Strategic control by quality aims to put the firm in continuous improvement conditions. Two TQM approaches will now be presented: the continuous improvement approach and the proactive improvement approach.

\subsubsection{Continuous improvement approach}

The strategic control with continuous improvement of processes is a Japanese approach of total quality which was spread out of Japan by K. Imai (Imai 1988) under its Japanese name Kaisen. It is not a formal method but a philosophy that all the employees of the firm must acquire. The fundamental principle of this method is based on the supposition that neither the product nor the production system is perfect and thus has to face continuous improvement. This quest for perfection has both external and internal aspects. On the external point of view, a firm has to be efficient towards its customers i.e. satisfying systematically the needs of the customers and forecast their wants and desires. This efficiency can be evaluated without any interaction with the way of controlling the firm and/or its production system. On an internal point of view, the firm must be organised such that it attains at the first shot and in the most efficient prosperous and rapid way the satisfaction of its customers. It is known as the efficiency of the control system.

The fields of application of the Kaisen are related to the reduction and prevention of bad products, reduction of cycle time and the respect of delays, the mastering of production costs, the increase of flexibility possibility of the production system and those of its robustness and reliability. In this classical context of TQM, the originality of the Kaisen is to go towards its aim using continuous innovation through its own employees who, at their own specific level, engage themselves in this grouped and systematic operation. Their contribution both individual and in group, arise in their daily production tasks. They are asked to observe what goes wrong and to propose improvements. Each actions taken can seemed unimportant but, on a long period, when we summed up the actions of every employee, the wanted effect is reached with continuous improvements of the production system (Imai 1997). Moreover, this way of involving the intelligence and creativity of employees without any hierarchical prejudices reduce two factors of bad quality which are resistance to change and the gradual decrease of motivation and attention from employees which execute a repetitive work.

On the strategic level, the control based on the Kaisen approach must organise the occurrence and collection of ideas and suggestions so that this is not lost by its bad use (Dunn 1997). Furthermore, the Kaisen approach concerning the entire production system of the firm, these ideas must be sorted into what concern the operational control from every other technological, economical, human... considerations that can also be subject to improvement propositions. Several organisation techniques have been developed and tested in Japan. This goes from suggestion systems, optional (ideas box) or obligatory (every employee is forced to propose an improvement idea every day), to the choice of a group of motivated and partially empowered employees (quality circles or progress group).

In all the cases of non trivial problems, the problem must first be identified, explicitly or implicitly or choosing it from a list of formerly identified problems, and define a measuring unit 
that can explain the problem and then use to implement the follow up of the solution. Then, an improvement aim must be specified and information concerning this improvement must be collected. This allows binding the needed conditions to develop improvement solutions and propose their implementation. After the final approval of the solution, the new working rules must be formalised and included in the control rules.

\subsubsection{Proactive improvement approach}

Against an extremely reactive market, the management by continuous improvement is not enough, because changes, technological gaps and steps that must be taken he to be forecast to put them in action on the appropriate time. To reach this, the firm has to focus itself on essential axes of progress defined by a limited number of aims established from prospective studies and aiming to bring some competitive advantages. Among the typical approaches, we can quote the conception turned toward supplier, the innovating project management and the transverse management. They are little adapted to the case of quality control as well as the Hoshin method spread under the name of "policy deployment" or under the name of "management by breakthrough". This type of approach is also at the base of the work of Harry (Harry 2000) which considers that Six Sigma does not aim at continuous improvement, but on the contrary that it must allow an breakthrough of the company.

The Hoshin method give the advantages of firstly allowing rapid and coherent actions due to the followed organisation and secondly having a good adequacy between problem knowledge shared by all and the distribution of their responsibilities concerning the gain of a consensual solution. On comparison to continuous improvement methods, the Hoshin method, coming as a complement, allows the forecast and strategically prepares the future evolutions of the control system (Tennant et al. 2000).

On the point of view of the Hoshin method's implementation on this strategic control, it is done in a relatively simple way. Indeed, the feedback decision loop, which deals with anticipation, is found over all other levels of decision. Then, the Hoshin method uses principally as problem resolution principle the WV model (figure 10) (Shiba 1993) which presents the originality of alternating systematically purely cognitive phases and site investigation phases.

Cognitive phase

Site inquiry phase

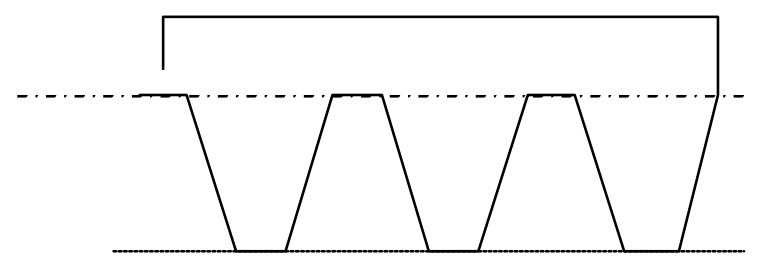

Figure 10. WV model for problems resolution

Finally, the analysis and synthesis methods used during these phases are, excepted the usual quality tools (Pareto diagrams, cause-effect diagrams...), quality management tools (Shiba 1996b). When the cultural specificity is eliminated, we find:

- for the relation and affinity diagram, topologic graphs issued for example from brainstorming,

- for tree diagram, decomposition graphs,

- for decision diagram, algorithms under the form of flow chart,

- for the arrow diagram, a PERT graph equivalence, 
- for the diagram using matrices, basic methods of multicriteria decision and factorial data analysis.

Alternating thought-experimentation is here justified by the idea that all decisions must be validated by facts. The comprehe nsion of these facts makes it obligatory to find their causes and thus completely validate the related phase.

Finally, the Hoshin method appears as good compromised between continuous improvement from which comes its philosophy, and the classical management by aims (MBO), with which it is directly linked while giving it a new breath. While the MBO method considers only the results obtained, the Hoshin method associates also the focalisation on the procedures and gives a collective and non hierarchical dimension to decision making with an autonomous training effect and the real consideration of customers.

\section{Continuous improvement and control by quality}

The strategies described above are all directly linked with the basic improvement cycle known as PDCA cyc le or Deming cycle divided into four phases:

P for Plan: allows the scheduling of the improvement project along with its theoretical description, its decomposition into atomic actions, the way it can be evaluated and related indicators, its means of imple mentation (resources participating to this implementation) and its time table.

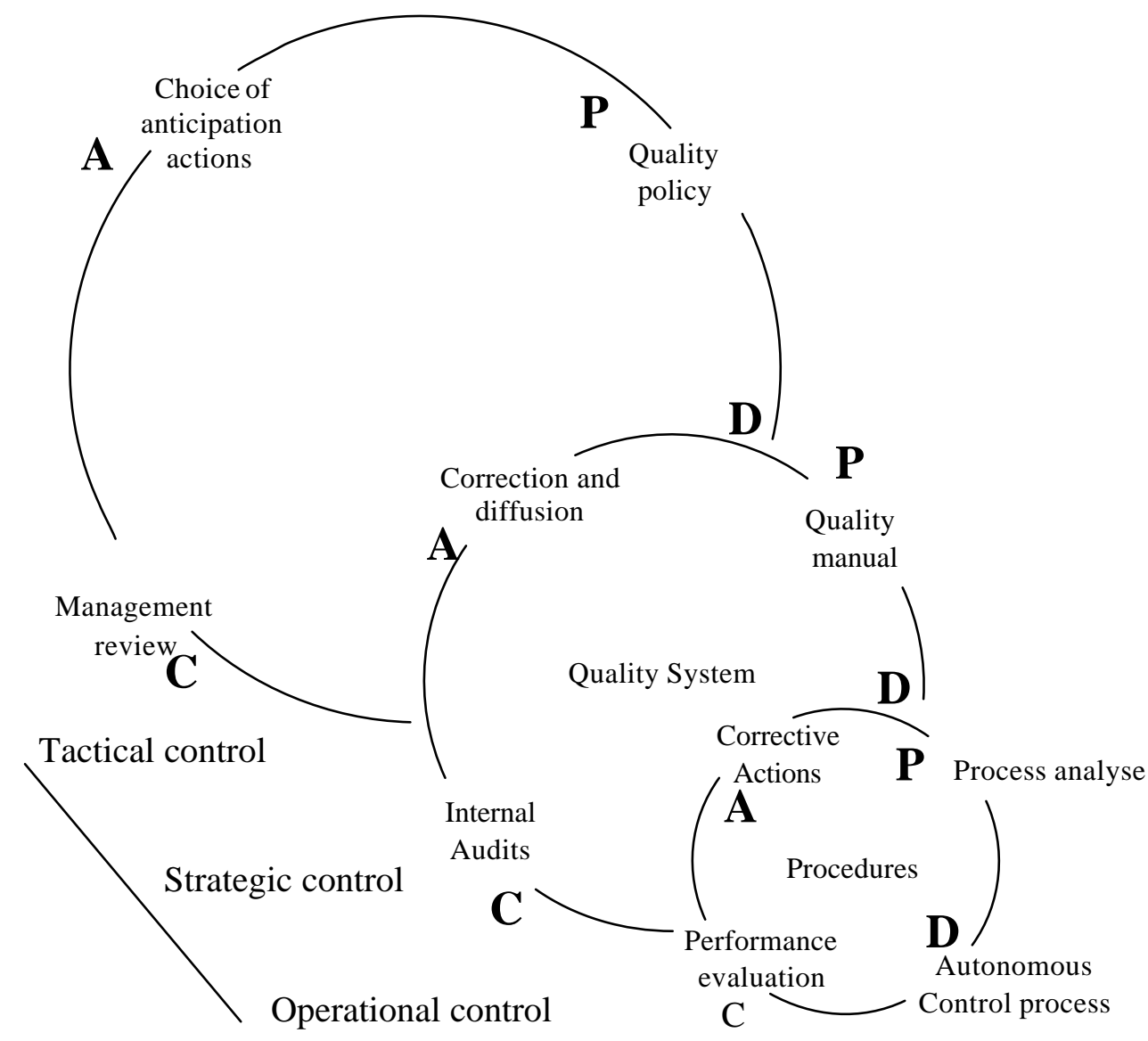

Figure 11. Reccursif Deming cycle for control by quality 
D for Do: implementation of the improvement procedure with the verification of the assumptio ns made and collection of results obtained.

C for Check: covers the verification of the results and validation of the improvement project; this evaluation can be either positive or negative according to whether the expected results were obtained.

A for Act: if the improvement project fails for some reasons. They have to be understood and used the knowledge acquired from them in future. If the project succeeds, then the results should be used to improve all other areas of the firm where it is possible. For this to work efficiently, these results should be standardise and spread in the firm. Finally, according to all improvement made and overall knowledge acquired, the next step has to be chosen.

\section{Conclusion}

An efficient control of a production system needs to bring the convergence of the different aims whose application needs can seemed, on first sight, diverging (Schippers 2001). The aim of control by quality is to contribute to the global efficiency of the firm by strengthening specific actions on cost and delays by using three factors: efficiency evaluation, resistance to perturbations and the implementation of continuous improvement procedures. To be efficient, these three actions should be used on the operational, tactical and strategic levels.

The evaluation of the efficiency is one of the first controls by quality rules. Only measures give indications allowing control i.e. allowing implementing a closed loop decision-making system:

- at the operational level, evaluation of the product's quality allowing to make preventive reactions,

- at the tactical level, audit validates the efficiency of the quality system,

- at the strategic level, customer satisfaction measures allow forecasting market evolution.

The second action aims to reduce the number of recurring perturbations or related consequences to stabilise control. This action needs the use of at the operational level, production processes control methods and tools to make the process resistant to risks, at the tactical level, a quality management system whose aim is to formalise the essential know-how of the firm, and at the strategic level, an environment controlling system (customers, market,...) to forecast the consequences of its evolution.

This stabilisation related to the implementation of a closed loop control system fuels the third action, which is the continuous improvement of the efficiency of the firm. The aim of this third action is to favour the evolution and adaptation of the firm towards the new constraints and to create a momentum of continuous progress, which will allow the firm to differentiate it from others. But to be able to do this essential task, time is needed but there is time only if the firm has eliminated recurrent perturbations using a lot of resources.

In order to apply efficiently these three actions: measure/stabilize/improve on the three levels Strategic/Tactical/Operational, it is necessary to create a synergy of many approaches, methods and tools of quality. Often the various approaches are opposite, whereas each one contributes efficiently to part of control by quality. Thus, rather than to oppose "six sigma" and "ISO 9000" as it sometimes is seen, one should on the contrary use their complementarities. The ISO approach contributes significantly to the phase of stabilisation on the whole of the levels, whereas the approach "six sigma" contributes more to the phases of measurement and improvement. In the same way the Taguchi's approach is extremely interesting at the operational level to increase the 
products and processes robustness and thus to take part effectively in the stabilization of the operational level. In fact, the difficulty does not consist in finding the method miraculous able to solve all the problems, but rather to be the conductor able to orchestrate a whole of complementary approaches in a harmonious co-operation of the strategic, tactic and operational levels of a control by quality.

The principles described in this paper allow reaching this triple aim: stabilise the process, create a permanent progress momentum and increasing the other overall efficiency of the firm. In these conditions, the control by quality is an essential element for increasing the efficiency of a firm with major consequences on control by cost (by the reduction of cost of no quality), control by flows (by reducing flows resulting from the reduction of failures and appearance of bad products) and control by delays (by a better adequacy between forecast and reality due to resistance to a better robustness of the production). Thus, a Total Quality approach has to be at the centre of the implementation and exploitation of the control system of a production system.

\section{References}

Adams, N. H., 1999. Quality Assurance Reviews: How They Differ From Peer Reviews. International Journal of Quality Assurance, Vol.6, $n^{\circ} 2$, pp75-85.

Auer, A., Karjalainen, J., and Seppanen, V., 1996. Improving R\&D processes by an ISO 9001-based quality management system. Journal of Systems Architecture, Vol.42, pp235-244.

Curkovic, S., and Pagell, M., 1999. A Critical Examination of the Ability of ISO 9000 Certification to Lead to a Competitive Advantage. Journal of Quality Management, Vol.4, $n^{\circ} 1$, pp51-67.

Daihani, D., Kieffer, J.P., and Pujo P., 1993. A conceptual approach of a new architecture of the computer aided quality management system, toward their better integration with the other production management functions. Newcastle International Conference on Quality \& its Applications, Newcastle.

Dunn A., 1997. Comment mettre en place un système de suggestion. Editions MFQ. (in french)

Forrest, W., and Breyfogle III, 1999. Implementing six sigma. Wiley.

Fukuda, R., 1990. CEDAC, a tool for continous systematic improvement. Productivity Press.

Harry, A., and Schroeder, R., 2000. Six Sigma. Double Day.

Hillmer, S., and Karney, D., 2001. In support of the assumptions at the foundation of Deming's management theory. Journal of Quality Management, Vol6, pp371-400.

Imai, M, 1988. Kaisen, the Key to Japan's Competitive Success. Random House, New York.

Imai, M., 1997. Gemba Kaisen, A Common Sense, Low-Cost Appreach to Management. Mc Graw Hill.

Ismail, M.Y., Baradie, M.E., and Hashmi, M.S.J., 1998. Quality Management in the Manufacturing Industry : practice vs Performance. Computers Iind. Engng, Vol.35, pp519-522.

Juran, J.M., 1990. Juran's Quality Control Hand Book. Mc Graw Hill.

Knowles, G., Antony, J., Vickers, G., 2000. A Practical Methodologiy for Analysing and Improving the Measurement System. International Journal of Quality Assurance, Vol.8, $n^{\circ} 2$, pp59-75.

Koetluk-Florescu A., 1995. Supplier Monitoring: Customer's Ticket to Software Quality. International Conference on Software Quality, Austin TX, Vol. 5, No. 0, pp. 375-384.

Mahoney, F. X., and Thor, C. G., 1994. The TQM Trilogy. Americain Management Association.

Matsuda, K., 1993. Production Management. PHP Institute Inc.

Mizuno, S., 1988. Management for Quality Improvement - The 7 new QC tools. Productivity Press Cambridge.

Osada, T., 1991. The 5 S's : Five Keys to a Total Quality Environment. Axiom Productivity Organization, Tokio.

Pillet, M., 2000. Appliquer la Maîtrise Statistique des Procédés. Les éditions d'organisation. (in french) 
Schippers, W.A.J., 2001. An integrated approach to process control. International Journal of Production Economics, Vol.69, pp93-105.

Shewhart, W., 1931. Economic Control of Quality of Manufactured Product. Van Nostrand.

Shiba, S., 1993. A New American TQM : 4 Practical Revolutions in Management. Center for Quality Management.

Shiba, S., 1996. Les outils du management de la qualité - Guide pédagogique. Editions MFQ.(in french)

Shirose, K., 1994. Le guide TPM de l'unité de travail. Dunod.(in french)

Stashevsky, S, and Elizur, D., 2000. The effect of quality management and participation in decision-making on individual performance. Journal of Quality Management, Vol.5, pp53-65.

Taguchi, G., 1987. System of experimental design. Unipub/Kraub, (tome I and II).

Tennant, C., Roberts, P.A.B., 2000. Hoshin Kanri: A Technique for Strategic Quality Management. International Journal of Quality Assurance, Vol.8, n², pp77-90.

Wang, F.K., and Lee, W., 2001. Learning curve analysis in Total Productive Maintenance. International Journal of Management Science, Vol.29, pp491-499.

Wilkinson, G., and Dale, B.G., 2002. An examination of the ISO 9001:2000 standard and its influence on the integration of management systems. Production Planning and Control, Vol.13, $n^{\circ} 3$, pp284-297. 